\title{
The Research of Reform in "Electromechanical Control Technology" Courses by Oceanic Features
}

\author{
Qingli Zhang ${ }^{\mathrm{a}}$, Weilei $\mathrm{Mu}^{\mathrm{b}}$ \\ Engineering College, Ocean University of China, Qingdao 266100, China; \\ azq16129@126.com, btbuleapple@126.com
}

Keywords: Teaching research; teaching and scientific research; oceanic features; electrical and mechanical control technology.

\begin{abstract}
The course of "Electromechanical control technology" is a compulsory course in mechanical engineering. Each university has its own characteristics in the teaching content. For the marine characteristics of our university, the teaching of the courses is studied, and knowledge about ocean is added in the course. It reflects that the courses have oceanic features. The teaching mode and contend are reformed to develop student's ability of design and practice and enhance student's interest in learning.
\end{abstract}

\section{Introduction}

The course of "Electromechanical control technology" is a compulsory course in mechanical engineering, also a necessary course to popularize electronic control knowledge for non-electrical major. It's a comprehensive application technology which is a professional knowledge combination of machinery and electrical, including remote control, automatic control, information processing to reflect [1]. Although different universities have different approaches in teaching content, teaching form, there is an identical purpose which is teaching student basic knowledges of mechanical and electrical control and with expertise in related disciplines. Therefore, different types and different professionals have different teaching points. The content and teaching methods of high vocational and applied colleges are mainly reflected in strengthening of electromechanical control for student's practical skills. Jin-Re Li [2] discussed the teaching of electromechanical control technologies. In order to meet the requirements of training practical technical principle, the case of typical process control and frequency control is increased. Yan $\mathrm{Xu}$ [3] put forward a training hierarchical teaching methods in electromechanical control technology. For student mastery of professional knowledge, students can deepen the knowledage of the mechanical, electrical, hydraulic professional courses. The comprehensive uses of mechanical, electrical, hydraulic control expertise, cultivate improve students' ability to analyze and solve practical problems. The basis of the theory of "Electrical Transmission and Control" was taught by Na Wang [4], who was teacher of Jinan University. And the practice course is reinforced. The proportion of the experiment is enhanced. The comprehensive, innovative pilot projects are also increased. In the course, the engineering applications is becoming more important, and the practice of mechanical and electrical engineering is added. The teaching content and practical application are connected more tightly.

Research University focuses on the design and development of electromechanical control technology theory. The training goal is to cultivate designers and developers with certain expertise. Under the implementation of the Ministry of Education Excellence Engineers Plan, the importance of the interaction of practice and theory is emphasized. In order to overcome the previous problem, the task of practice courses is enforced in various universities. Xian-Zheng Wang wrote a textbook named "mechanical and electrical control technology" in Shanghai Jiao Tong University. As he mentioned, the time of practice should be occupancy $20 \%$. Combined with the characteristics of the course and the development of Mechanical Engineering, the new system of "electromechanical control technology" course is formed base on "The Electric apparatus of Machine" in Southeast University. The teaching ideas of curriculum are clarified. The ability of electromechanical practical and innovation for students is developed. In the form of teaching, the advantages of the combination 
in teaching and research play an important role in Research Universities. The characteristic of "mechanical and electrical control technology" has been shown in various areas. Yang Zhang [4], etc. had made the application of PLC technology to mining machinery. Ying Nan Zhou [5] discussed the mechanical and electrical control systems in the hydraulic system.

The 21st century is the oceanic century. The marine resources exploitation requires numerous instruments and equipments. Also, the development requires electromechanical control technology. As a research university, Ocean University of China aims to develop student's skill, research and develop for marine resources. To acquire the quality of the teaching, the experiences has been absorbed from various universities. And the reform of "mechanical and electrical control technology" course is conducted through teaching contents and teaching methods. The senior engineer who has a certain practical basis, innovative mechanical and capacity of electrical equipment design in marine is cultivated. Since the case used in teaching is from research, the course of "mechanical and electrical control technology" has been contacted to marine characteristics. The specific process of combining teaching and research will be introduced below.

\section{Teaching is combined with research, theory is proved by practice}

As a high-level University, the OUC's research projects mainly relate to the marine professional, from the technology of marine survey and utilization of marine resources. It has formed a research team of marine equipment, instrument, offshore platforms, underwater robots and detection. The studies of these projects are related to the mechanical and electrical control technologies. It applies mechanical electric control technology of those projects into this course as teaching cases, which makes class teaching more effective and practical instead of a pile of empty theory. Students have less difficulty to learn the theory of knowledge and their learning interests are stimulated. Skipping is significantly reduced and the teaching order and teaching quality are highly increased. For example, when a professor taught the sequential function chart of PLC, before teaching, the professor put forward the working process of kelp seeding machine by videos, and then proposed sequence control work to be completed and the sequential function chart to the students, giving students leaving suspense; then he taught the theoretical basis of achieving sequential control. After solved the students' suspense, the content of this lesson is basically finished. Taking the advantage of students' interest, practical courses are immediately arranged. Let the students write program by themselves and input PLC debugging. Through this kind of teaching, it makes teaching more easily. The interaction between the teacher and the students is tightly connected. The interaction is not only in the classroom, but also the topic that they talk after class is also the application of sequence control.

When the research project as examples is introduced into undergraduate teaching, the lecture and learning is easy. And it overcomes many negative phenomena, such as the cramming education, the lacking of concentration, absence from school and sleeping in class. At the same time, students understand the scientific research content and the method. Students can not only master the knowledge of the course but also learn how to do things. It is important to train the excellence engineers.

Putting the research projects as examples introduced into undergraduate teaching, it made teachers speak more breezily and students learn more easily. And it overcomes many negative phenomena, such as teachers' cramming education, students' lacking of concentration, absence from school and sleeping in class. At the same time, the students could understand the teacher's scientific research content and the method. At the same time, students can not only master the knowledge of the course but also learned how to do things; it has important significance in training excellence engineers.

\section{Research is serviced by teaching to cultivate excellent engineer}

The aim is to develop marine senior talents for comprehensive knowledge and to serve the local economy. With the implementation of excellent engineers plan, higher request for talents' cultivation is put forward. So it is not enough to teach traditional mechanical and electrical control technologies, 
we should also increase the cultivation of student's innovative design. After completing the basic teaching plan, students participating in excellence engineers plan should be required to attend to the teacher's scientific research project, and finish some subjects involved in mechanical and electrical control technologies. Through this project design, on the one hand, students will apply the theoretical knowledge to the design; on the other hand, they will learn the method of innovation in the design, which is of great significance to the cultivation of excellent engineer. Students' involvement in the study could enrich the research plan, optimize the study content and share teacher's partial work, thus achieve a win-win result.

By designing a winch used for the Marine environmental observation, five students make of the mechanical and electrical control system after dividing the task. From simple relays, contactors, and pure hardware control system to a PLC-based control system, they proposed several plans. Considering the machine environment of the system, they finally worked out the optical plan under the guidance of their professors. And then they designed several ways on the basic of the optimal program. Based on the principle of simplification and clearness, they eventually worked out a certain way to realize the plan. The directors of these five students participated in the making process and made comparisons between the selection of the plan and the design of the system, which straightened students' application and the degree of mastery of the knowledge. This mode has great significance for cultivation of innovative talents.

\section{Teaching content is reformed according to marine characteristics}

We take examples of marine researching in our courses which brings ocean features in the control technology. It is not only introduced science and technology but engine controlling in the marine environment applied science. The content of the course fully represents our marine characteristics which may enhance our service as a marine institute.

Particular requirements in marine environment and marine engineering controlling are different from that in other fields. There are three different parts of the technology: corrosion proof, sealing and cooling. Hence, the content of corrosion proof is increased, in particular, the structure of sealing cabin, cooling ways and so on. The layout of these contents is located after the instruction and in front of the basic knowledge of engine control.

Along with the realization of teaching content, the teaching content is also reformed. The teaching form of mechanical electric control is mainly teaching in class, experiment, and combination of teaching and practice. Besides, it also participates in the scientific research, which intensifies the practical innovation training efforts.

Specific content and implementation of the reform is shown in Table 1.

Table 1 Contents and realization forms of electromechanical control technology course

\begin{tabular}{c|c}
\hline Content & Method/time \\
\hline $\begin{array}{c}\text { Introduction of Electro-mechanical } \\
\text { technology and corrosion, sealing, cooling } \\
\text { method on Marine environment }\end{array}$ & Multimedia teaching/4 \\
\hline $\begin{array}{c}\text { Commonly used low voltage apparatus } \\
\text { and control circuit }\end{array}$ & Multimedia teaching/4 \\
\hline $\begin{array}{c}\text { Commonly used voltage electrical } \\
\text { knowledge and control circuit experiment }\end{array}$ & Experiment/2 \\
\hline $\begin{array}{c}\text { Motor drive and speed control } \\
\text { electrical control circuit }\end{array}$ & Multimedia teaching/4 \\
\hline $\begin{array}{c}\text { Innovation experiment of low voltage } \\
\text { electrical control circuit }\end{array}$ & Innovation experiment/2 \\
\hline $\begin{array}{c}\text { Principles and Applications of } \\
\text { programmable controllers }\end{array}$ & Multimedia teaching/4 \\
\hline S7-200PLC Hardware, wiring and & Multimedia teaching/6 \\
\hline
\end{tabular}




\begin{tabular}{c|c}
\hline programming software & Multimedia teaching/6 \\
\hline $\begin{array}{c}\text { PLC Sequence control and programming } \\
\text { method }\end{array}$ & Experiment/2 \\
\hline $\begin{array}{c}\text { Sequence control experiment of kelp } \\
\text { seedling machine }\end{array}$ & Multimedia teaching/4 \\
\hline $\begin{array}{c}\text { The design of S7-200 common control } \\
\text { circuit }\end{array}$ & Classroom practice/4 \\
\hline Design practice of PLC Control circuit \\
\hline $\begin{array}{c}\text { PLC control experiment of marine } \\
\text { environment observation winch }\end{array}$ & Innovation experiment/4 \\
\hline
\end{tabular}

\section{Conclusion}

Examples of the research are applied to teaching and students take part in research team to increase the quality of class. With their own practices, teachers feel very confident, and the passion for teacher in class is inspired. Students agree with what they learn is what they use. It is cultivating their interest in learning. Sleep and skipping classes have been decreased significantly. In recent years, there is $20 \%$ of graduate design related to the mechanical and electrical control technology, and they all passed the exam. Seldom graduate designs related to this field before. It shows that the teaching reform has made great achievement.

\section{Acknowledgment}

Research on this topic was funded by professional comprehensive reform project of Ocean University of China (2013ZD03) and undergraduate teaching reform of Colleges and universities in Shandong Province (2015M010).

\section{References}

[1]. Ding-Hua Li, Application analysis of electromechanical control, Technology and Enterprise .2012.19.095 319.

[2]. Jing-Re Li, Research on teaching mode reform of "Electromechanical control technology", learned journal of Nanjing Institute of Industry Technology .2009 Vol.9, No.2 92-94.

[3]. Yan-Xu You-Xia Pang, Guo-Qiang Chen Pu-Hua Tang and Xing-Fa Yang, the create of training hierarchical teaching model on mechanical specialty electromechanical control technology . Hunan Institute of Engineering 2014 V01.24. No. 1101-103

[4]. Yang-Zhang Liang-Fang, Application of PLC technology which is covered in mine mechanical and electrical control technology .Application technology. 2014 Article 8283

[5]. Ying-Nan Zhou, Application of electromechanical control on the hydraulic shock. Machinery Industry Standardization \& Quality 2013.6 46-50 